\title{
Cystic lymphangiomas of the tongue: 3 rare cases and a literature review of classifications and therapeutic possibilities
}

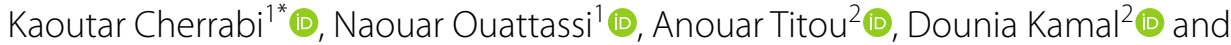 \\ Mohamed Noureddine El Alami ${ }^{1}$ (1)
}

\begin{abstract}
Background: Cystic lymphangiomas of the tongue are rare. The treatment consists of complete resection and management is generally interdisciplinary due to vital, functional, and esthetic comorbidities.

This work is a report of three rare cases of cystic lymphangioma of the tongue, with curious mode of presentation and good outcome, as well as a literature review of clinical features, classifications, and therapeutic possibilities.

Case presentation: This work presents three patients. The first one presented with a lymphangioma in the junction between base and body of tongue; the clinical aspect was first similar to hemangioma, and then the diagnosis was re-established after slight enlargement of the mass. The patient was treated with sclerotherapy with great outcome.

The second patient presented with a large lymphangioma which presented a clinical resemblance with a tumor of the tongue, the diagnosis was established upon radiological aspect and confirmed upon histological findings.

The third patient presented with a macroglossia which appeared 3 years after excision of the cystic hygroma of the neck; the patient was surgically treated with excellent outcome.

Conclusion: Cystic lymphangiomas are rare hamartomatous lymphatic malformations, and they have a predilection for head and neck but the lingual localization is quite rare. Treatment is complete excision. Management is generally interdisciplinary. The main objective is to prevent alteration to function, to treat esthetic comorbidities, and prevent speech impediment especially in very young children.

This is the cases of three young children with a rare lingual cystic lymphangioma, with adapted treatment and satisfactory outcome, with a literature review of clinical presentation, classifications, and therapeutic approaches.
\end{abstract}

Keywords: Cystic lymphangiomas, Head and neck, Anatomy, Radiology, Tongue, Congenital malformation, Macroglossia

\section{Background}

Lymphangiomas are rare congenital lymphatic hamartomatous proliferations that were first described by Virshow in $1845[1-5]$. They have predilection for head and

\footnotetext{
*Correspondence: Kaoutarcherrabi.bz@gmail.com

1 ENT and Cervico-Facial Surgery Department, Faculty of Medicine

and Pharmacy, Sidi Mohamed Ben Abdellah University, Fez, Morocco

Full list of author information is available at the end of the article
}

neck regions [2-4]. Growth is generally slow, but can be accelerated due to infectious or hemorrhage episodes [6].

\section{Case presentation}

The first patient was 1-year-old when he first presented with a lesion: a small blood-filled vesicular lesions in the intersection between the body and the base of the tongue. It appeared in the first year of life and was slightly painful during feeding. The lesion was first diagnosed as a hemangioma based on its clinical aspect, and a course 
of treatment of beta-bloquers was started in pediatric department. A stabilization of lesion's size was observed. After 4 years, the patient presents a slight increase in size, with a slight speech impediment, and persistent pain. The clinical exam showed a vesicular lesion, with translucide and blood-filled vesicles, which indicated that it was in fact a lymphangioma. The patient had a cervicofacial MRI which showed a cystic lesion of the junction between the body and the base of the tongue, hyperintense on T2, isointense to muscle in T1 (Fig. 1).

Patient was started on sclerotherapy with bleomycin, with good outcome after three sessions. Follow up of 3 months was satisfactory.

The second patient was 8 years old. She presented with a large tumor of the tip of the tongue with a sub-acute increase in size for the last 2 months with difficulties in alimentation, speech, breathing in supine position, as well as impossibility to close her mouth.

The patient underwent cervico-facial MRI that showed a cystic mass attached to the tip of the tongue, without any cervical lesions associated (Fig. 2).
The patient underwent surgical excision with Jian glossectomy technique, with minimum damage to underlying tissue. Follow-up consisted on post-operative dressings and othrophonic rehabilitation. The 3 months post-operative follow-up was satisfactory.

The third patient was 4 years old when he first presented with cystic hygroma to his neck, floor of mouth, parotid region, and masseteric region, for which he was admitted to surgery for excision. After 3 years, the patient presented with macroglossia. The lingual mass was large and it has been increasing in size in the last 3 months, articulation was impossible, alimentation very difficult, as well as respiratory distress. The clinical examination found no recurrence in cervical region, no other lesion was found in the oral cavity.

The patient had cervico-facial CT-scan which showed a heterogeneous mass of the tongue, taking on the totality of its body and base, with bulging in oropharynx. The patient underwent reductive surgery, through keyhole glossectomy technique with good follow up for 6 months, during which the patient was admitted in speech therapy

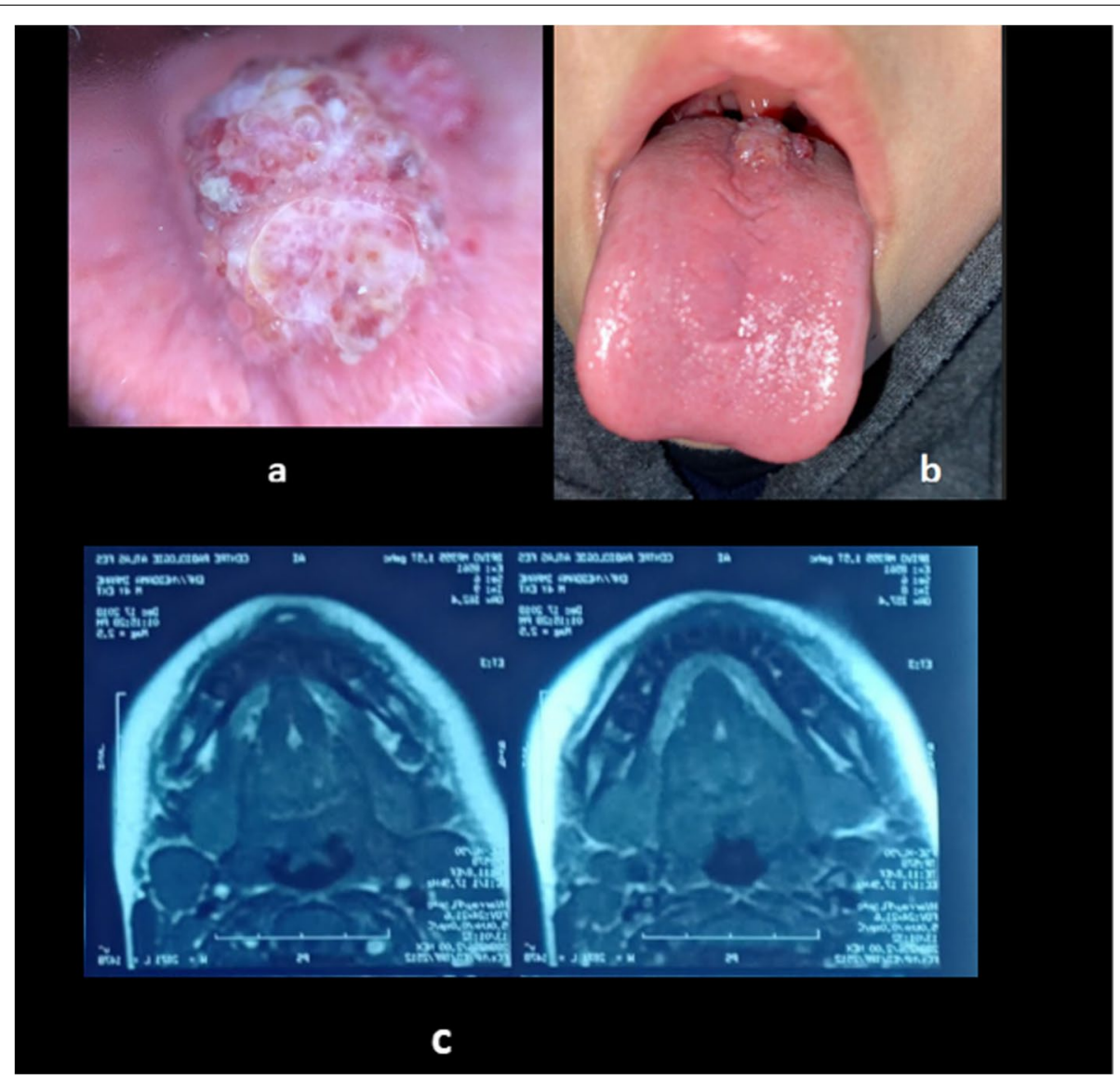

Fig. 1 Clinical and radiological findings in patient 1. a Dermoscopic aspect of the microcystic lymphangioma of the tongue. $\mathbf{b}$ Clinical localization of microcystic lesion of the tongue. $\mathbf{c}$ Coronal sections of MRI images, showing the lesion in the proximal extremity of the tongue 


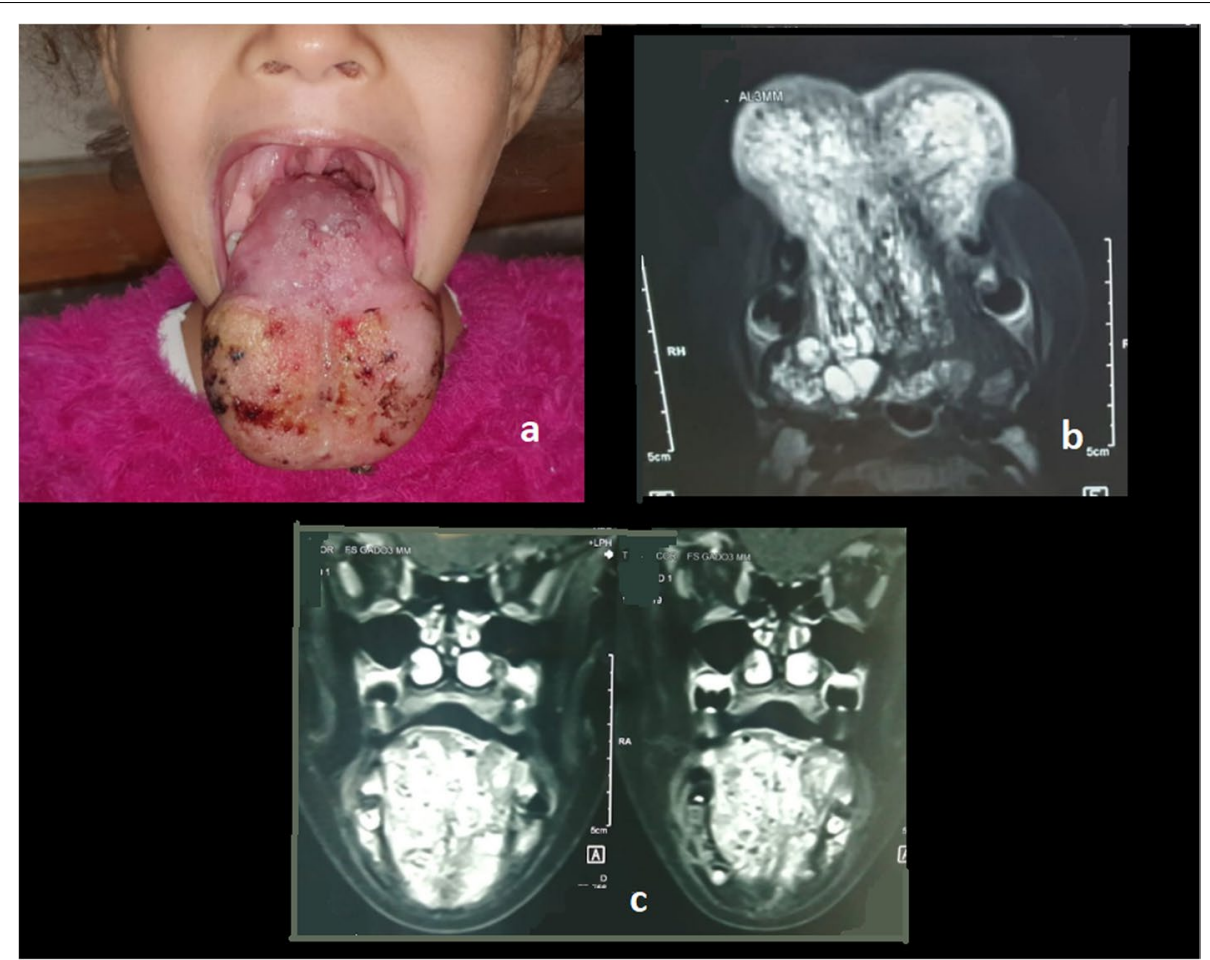

Fig. 2 Clinical and radiological findings in patient 2. a Clinical lesions of the patients 2. b Axial sections of MRI showing infiltration to the floor of mouth of the cystic lesion of the tongue. c Coronal sections of MRI showing the cystic lesion taking on the totality of the tongue

for slight speech impediment, with satisfactory evolution (Figs. 3 and 4).

\section{Discussion}

Fifty percent of cystic lymphagiomas are noticed at birth, and $90 \%$ are discovered by 2 years of age, generally in the first decade of life $[1-3,7]$. The most frequent site is the posterior triangle of the neck between the posterior border of the Sterno-cleido-mastoid muscle, the middle part of the clavicle, and the anterior edge of the trapezius [2]. They can also exist in the anterior triangle of the neck, in the parotid region, as well as the sub-mandibular region $[1,2,7]$. Cases of oral cavity lymphangioma are rare. They are generally in the tongue, palate, gingiva, lip, and alveolar ridge of mandibule $[1,2,5]$. In the tongue, the most common localization is in the anterior two thirds [2].

Precise embryological origin is still unknown. However, theories are studied [3].

Lymphangiomas are formed because of congenital obstruction or sequestration of the primitive lymphatic enlargement. Two major theories have cited to explain the origin of lymphangiomas $[1-3,5,7]$.

\section{1 st theory}

Lymphatic system develops from 5 primitive sacs that arise from the venous system [2]. Lymphatic system constitutes of endothelial out-pouching and travels centrifugally from jugular sac [2].

\section{2nd theory}

Lymphatic system derives from mesenchymal clefts in venous plexus reticulum and spreads centripetally towards the jugular sac [2].

Diagnosis is generally established upon superficial characteristics of the lesion. Radiology is indicated in case of inexperienced clinician or atypical lesions [8]. Clinical presentation of lymphangioma depends on extension of the lesion; superficial lesions are elevated nodules, while deeper ones are soft tissue masses [2,3].

The patient can present with a history of enlargement due to trauma or infection, recurrent infections, airway compression, feeding difficulties, interference with normal or developmental speech, and esthetic problems [8]. Early diagnosis and management are essential for good outcome [8]. Biopsy is not indicated because of the great risk of bleeding correlated to it [8].

Macroscopic aspect shows multiple small vesicles of varying sizes [9], covering the surface of the tongue, they may be either translucide or blood-filled. While localized in cases, they can be exophytic lesions with nodular surface due to the presence of vesicles in extensive cases [8]. Macroglossia of the anterior two thirds 

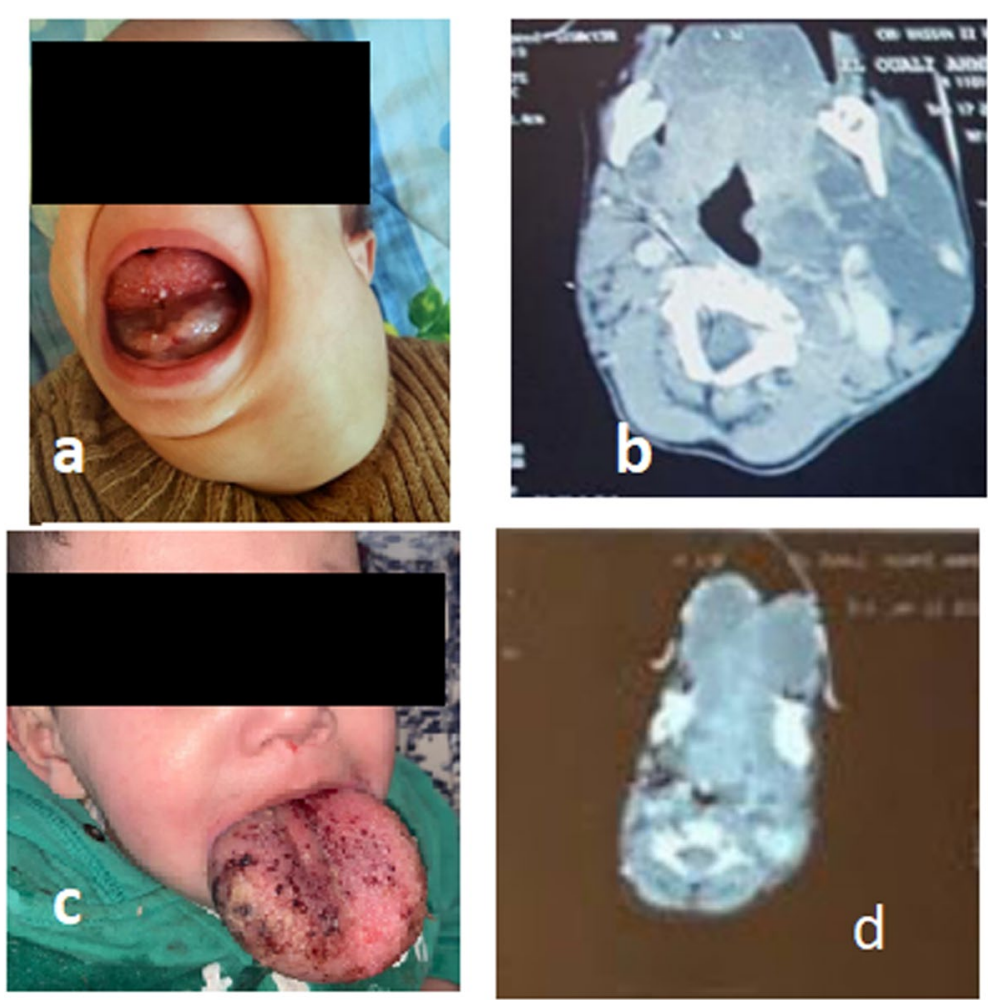

Fig. 3 Radiological findings in patient 3. a Preoperative clinical image showing showing cystic lesion in floor of mouth and adjacent cervical region. b Preoperative CT-scan section showing a cystic lesion in cervical region. c Post-operative clinical image showing macroglossia. $\mathbf{d}$ Post-operative CT-scan showing cystic aspect of the tongue

of the tongue causes speech impediment, poor oral hygiene, and bleeding accidents with oral trauma [2].

It is important to define the association with dental problems, especially for children with macroglossia to prevent carries and gingivitis [6]

Several classifications have been described $[1,2,4,10]$.

Histological classification is not correlated with clinical presentation or therapeutic approach $[1,4,10]$.

- Lymphangiomas simplex (lymphatic channels with thin walls and capillary size).

- Cavernous lymphangiomas (dilated lymphatic channels with fibrotic adventitial coats.

- Cystic lymphangiomas: composed from cysts varying from millimeters to several centimeters in diameter.

- Lymphangiosarcoma: lymphangioma associated with angiosarcoma, which a rare malignant tumor that develops after prolonged lymphatic obstruction.

De Serres Classification of lymphatic malformations is based on localization and extension $[2,8]$.

Class I: infra-hyoid unilateral lesions.
Class II: supra-hyoid bilateral lesions.

Class III: supra-hyoid or infra-hyoid unilateral lesion.

Class IV: supra-hyoid bilateral lesions.

Class V: infra-hyoid bilateral lesion.

Clinical classification [8]:

A classification based on clinical aspect, and based on response to sclerotherapy, is more used:

- Microcystic: do not respect tissue planes, diffuse, and are difficult to excise.

- Macrocystic: are localized and surgically easier to excise.

- Mixte.

Classification of microcystic lymphangioma is correlated with treatment option and indicates the possibility of curative treatment (Table 1).

In Wiegand et al. classification, I, IIa, IIb, and III belong to Serres et al. In stage II, they have different treatment modalities and outcomes [8].

I and IIa are easier to treat and their complete resection is possible. IIb and III are more difficult due to the 


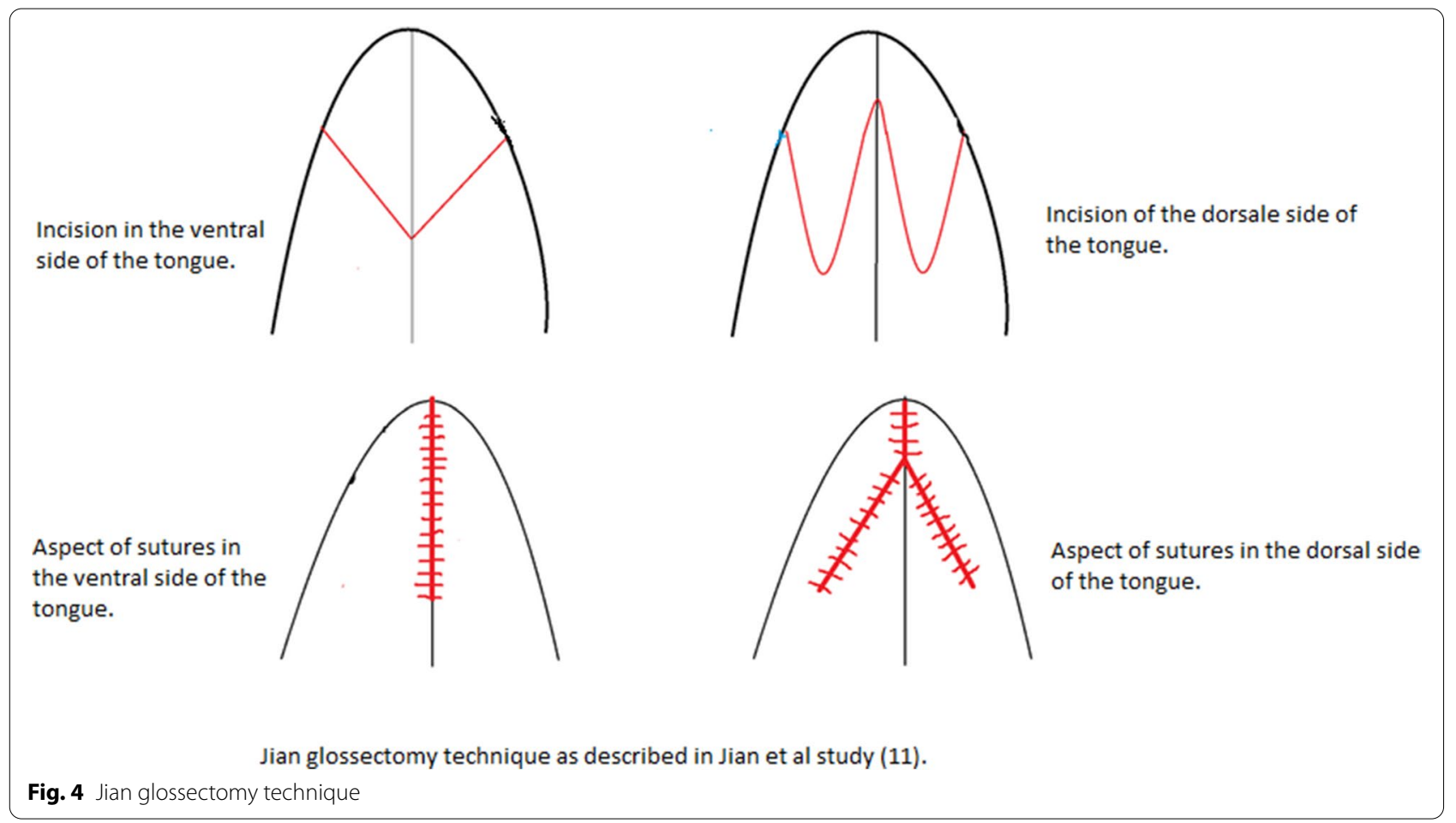

extension of the disease and the involvement of structures [8].

MRI is the exam of choice, if treatment is indicated and in cases of large lesions in order to examine extensions [8]. The aspect on MRI consist on highly increased intensity in T2-weighted images, while in T1-weighted images, lesions have the same intensity or slightly lower intensity than muscle [7, 8].

The standard objective of management of head and neck lymphangiomas is total excision whenever it is possible [3, 4]. Incomplete removal is associated with a high risk of recurrence [10]. Restoration or preservation of function, esthetic integrity, and management of lymphatic malformations have changed in the last few years [3].

Treatment depends on size and involvement of anatomical structures $[2,8]$. Conservative management should only be considered for asymptomatic cases before definite treatment. The risk of acute enlargement in cases of infection or hemorrhage should be contemplated [8]. Surgery is generally delayed until 3 years old of age $[2,4,8]$.

Several techniques have been described to manage lympangiomatous and hemolymphangiomatous lesions of the tongue. Peripheral glossectomy are used in cases of lesions that occupy length and width of the tongue. Keyhole glossectomy, which is used when all dimensions of the tongue are involved, and central strip glossectomy in cases that involve hemihypertrophy of the tongue [11]. Jian Glossectomy technique combines marginal and central resection, and maybe used for lesions in the anterior and middle parts of the tongue [11].

The association of antibiotic therapy and steroid course should be considered for all stages in cases of enlargement [8].

Table 1 Table of classification of microcystic lymphangiomas [8]

\begin{tabular}{|c|c|c|}
\hline & Description : & Treatment \\
\hline Stage I [8] & $\begin{array}{l}\text { Isolated superficial microcystic lymphatic malformations of the } \\
\text { tongue. }\end{array}$ & $\begin{array}{l}\text { IlaCO2 laser is curative with excellent outcome. (Susanne Wiegand } \\
\text { et al.). }\end{array}$ \\
\hline \multirow[t]{2}{*}{ Stage II [8] } & $\begin{array}{l}\text { Isolated superficial lymphatic malformations of the tongue with } \\
\text { muscle involvement. }\end{array}$ & $\begin{array}{l}\text { Ila CO2 laser is curative with excellent outcome. (Susanne Wiegand } \\
\text { et al.). }\end{array}$ \\
\hline & & Ilb useful combined and staged approach. (Susanne Wiegand et al.). \\
\hline Stage III [8] & Microcystic malformation of the tongue and the floor of mouth. & Ilb useful combined and staged approach (Susanne Wiegand et al.). \\
\hline Stage IV [8] & $\begin{array}{l}\text { Extensive microcystic lymphatic malformation involving the } \\
\text { tongue, floor of mouth, further to cervical structures. }\end{array}$ & Ilb useful combined and staged approach (Susanne Wiegand et al.). \\
\hline
\end{tabular}


Table 2 Treatment possibilities for cystic lymphangiomas of the tongue $[2,5,6,8]$

\begin{tabular}{|c|c|}
\hline Treatment mode: & Pitfalls of treatment. \\
\hline - Surgical excision $[2,5,8]$. & $\begin{array}{l}\text { Surgical techniques: } \\
\text { - Wedge resection. } \\
\text { - Bilateral marginal resection. } \\
\text { - U-shaped resection. } \\
\text { - Jian or Dignan glossectomy. }\end{array}$ \\
\hline - Cryotherapy $[2,5,8]$ & $\begin{array}{l}\text { Is a minimal invasive therapy option that is primarily indicated in stages I and II lesions. (Li Hisiung } \\
\text { et al.) Is used for small locailzed lesions, as it does not seem to affect lesions with extension. }\end{array}$ \\
\hline - Electrocautery $[2,3,8]$ & Only palliative benefit \\
\hline - Radiation therapy $[2,3,5,8]$ & $\begin{array}{l}\text { Irradiation is no longer used, as it is unable to completely distroy lesions, with the possibility of } \\
\text { malignancy induction. }\end{array}$ \\
\hline - Sclerotherapy O.K $432[2,5,8]$ & $\begin{array}{l}\text { Is indicated for macrocystic lesions, since sclerosing substance cannot diffuse through cystic lumens. } \\
\text { Can be a good alternative to surgery, with Bleomycin: } 0.25-0.6 \mathrm{mg} / \mathrm{kg} \text { or } 0.75-0.8 \mathrm{U} / \mathrm{kg} \text { with } 2 \text { weeks } \\
\text { to } 2 \text { months intervalle, with a cumulative dose of } 30 \mathrm{mg} \text { or } 150 \mathrm{U} \text {, or } 5 \mathrm{mg} \text { per } \mathrm{kg}(15 \mathrm{U} / \mathrm{kg}) \text {. } \\
\text { Side effect: pulmonary complications, which is redoutable and related to cumulative dose. }\end{array}$ \\
\hline - Embolization $[2,8]$ & Has been investigated and could be discussed in larges cases. \\
\hline $\begin{array}{l}\text { - Steroid administration. (Usha et al.) (Susanne } \\
\text { Wiegand et al.). (Li Hisiung et al.) }\end{array}$ & Local injection of steroid has been described by Khurana et al. \\
\hline - Laser surgery $[2,8]$ & $\begin{array}{l}\text { Complete excision with } \mathrm{CO} 2 \text { laser shows advantages of less edema, less trauma to underlying tis- } \\
\text { sues, and less blood loss compared to surgery. Difficulty of excision of microcystic lesions due to the } \\
\text { difficulty in diffrentiation between healthy and infiltrated tissue. }\end{array}$ \\
\hline - Radio-frequency tissue ablation technique $[2,8]$ & Is a minimal invasive therapy option that is primarily indicated in stages I and II lesions. \\
\hline
\end{tabular}

Oral cephalosprin: Cefuroxim axetil $500 \mathrm{mg}$, two times a day for 7 to 10 days, or cefuroxim $80 \mathrm{mg} / \mathrm{kg}$ a day for a maximum of $4.4 \mathrm{~g}$ in 3 doses by IV [8].

Steroid: $5 \mathrm{mg} / \mathrm{kg} /$ day with a maximum of $250 \mathrm{mg}$ a day [8].

When surgery is indicated, the best choice the radical approach. The need for repeated surgery alters the underlying structures [8] (Table 2).

Cystic lymphangiomas of the tongue can be associated with several complications:

- Rapid enlargement due to upper tract infections or hemorrhage with possible airway obstruction [3].

- Functional complications $[2,3,8]$.

- Esthetic complications [1-3, 8].

Recurrence rate after total excision is $0-27 \%$, and after partial excision $50-100 \%$ [4].

\section{Conclusion}

Management of large lymphatic malformation of the tongue is accomplished through complete excision, and demands inter-disciplinary approach $[1,8]$. Macroglossia and large lymphangiomas of the tongue could lead to skeletal and dental problems like prognathism and malocclusion [8]. Maxillo-facial surgeons and ortho-dentists should be involved $[4,8]$.

This work is a report of three rare cases of cystic lymphangioma of the tongue, with curious mode of presentation and good outcome, as well as a literature review of clinical features, classifications, and therapeutic possibilities.

\section{Acknowledgements \\ Not applicable.}

\section{Authors' contributions}

KC conceived and designed analysis, collected data, performed analysis, wrote the paper, and performed surgery. NO performed surgery. AT contributed in data collection. DK supervised surgery and contributed to designing analysis. MNE supervised designing analysis. All authors have read and agreed to its content.

\section{Funding}

Not applicable. No financial conflict of interest.

Availability of data and materials

Not applicable.

\section{Declarations}

Ethics approval and consent to participate

Not applicable.

\section{Consent for publication}

The patients' parents provided written informed consent to publish this case report, as well as for the publication of information.

\section{Competing interests}

The authors declare that they have no competing interests.

\section{Author details}

${ }^{1}$ ENT and Cervico-Facial Surgery Department, Faculty of Medicine and Pharmacy, Sidi Mohamed Ben Abdellah University, Fez, Morocco. ${ }^{2}$ Maxillo-facial Surgery Department, Faculty of Medicine and Pharmacy, Sidi Mohamed Ben Abdellah University, Fez, Morocco. 
Received: 22 October 2021 Accepted: 24 December 2021

Published online: 14 February 2022

\section{References}

1. Ikeda $\mathrm{H}$ et al (2006) Cystic lymphangioma arising in the tip of the tongue in an adult. Int J Oral Maxillofac Surg 35(3):274-276

2. Usha V, Sivasankari T, Jeelani S, Asokan GS, Parthiban J (2014) Lymphangioma of the tongue-a case report and review of literature. J Clin Diagn Res 8(9):ZD12-ZD14. https://doi.org/10.7860/JCDR/2014/9890.4792

3. Cheng L-H et al (2013) Lymphangiomatous macroglossia associated with extensive cervicomediastinal cystic hygromas. J Chin Med Assoc 76(11):653-656

4. Kataria P, Passey JC, Agarwal AK (2009) Lymphangioma circumscriptum of the tongue: successful treatment using intralesional bleomycin. J Laryngol Otol 123(12):1390

5. Yaita T et al (2007) Histomorphometrical study in cavernous lymphangioma of the tongue. Oral Dis 13(1):99-104

6. Postlethwaite KR (1986) Lymphangiomas of the tongue. Br J Oral Maxillofac Surg 24(1):63-68

7. Beech AN, Farrier JN (2016) An interesting association of cystic hygroma of the neck and lymphangioma causing a paediatric swollen tongue. Case Rep Pediatr 2016. https://doi.org/10.1155/2016/7930945

8. Wiegand S, Eivazi B, Zimmermann AP et al (2009) Microcystic lymphatic malformations of the tongue: diagnosis, classification, and treatment. Arch Otolaryngol Head Neck Surg 135(10):976-983. https://doi.org/10. 1001/archoto.2009.131

9. Bonet-Coloma C et al (2011) Clinical characteristics, treatment, and evolution in 14 cases of pediatric orofacial lymphangioma. J Oral Maxillofac Surg 69(6):e96-e99

10. Bektaş-Kayhan Ket al (2014) Lymphangioma of the tongue: report of four cases with dental aspects. Turk J Ear Nose Throat 24(3):172-176

11. Jian XC (2005) Surgical management of lymphangiomatous or lymphangiohemangiomatous macroglossia. J Oral Maxillofac Surg 63(1):15-19. https://doi.org/10.1016/j.joms.2004.04.024 PMID: 15635551

\section{Publisher's Note}

Springer Nature remains neutral with regard to jurisdictional claims in pub-

lished maps and institutional affiliations.

\section{Submit your manuscript to a SpringerOpen ${ }^{\odot}$ journal and benefit from:}

- Convenient online submission

- Rigorous peer review

- Open access: articles freely available online

- High visibility within the field

- Retaining the copyright to your article

Submit your next manuscript at $\boldsymbol{\nabla}$ springeropen.com 